\title{
Canadian Pain Society Conference
}

\author{
May 23 - 26, 2007, Ottawa, Ontario
}

\section{COMMUNITY PUBLIC EVENT WEDNESDAY MAY 23, 2007}

6:30 PM - PAIN RELIEF - A BASIC HUMAN RIGHT

7:15 PM - PAIN MANAGEMENT AND REGULATORS

1

Chair: David Mann C Eng FIET

President FM-CFS Canada, Ottawa, Ontario

Speakers: Hon Ed Broadbent PhD PC CC, Rocco Gerace MD

Registrar

BRIEF DESCRIPTION: Conference delegates, pain patients and their families and friends are invited, as well as the physicians caring for them. We extend a particular invitation to physicians who have had concerns about the CPSO and regulatory impact on prescribing pain medications.

\section{A}

PAIN RELIEF - A BASIC HUMAN RIGHT

Hon Ed Broadbent PhD PC CC

Former Leader of the New Democratic Party of Canada, Founding

President of the International Centre for Human Rights and

Democratic Development, Montreal, Resides in Ottawa, Ontario

\section{B}

PAIN MANAGEMENT AND REGULATORS

Rocco Gerace MD Registrar,

College of Physicians and Surgeons of Ontario, Toronto, Ontario

\section{PAIN EDUCATION DAY} THURSDAY MAY 24, 2007

\section{8:00 AM - KEYNOTE SPEAKER}

\section{2}

\section{CELL-SIGNALLING MECHANISMS IN PAIN \\ NEUROPLASTICITY}

Chair: Roman Jovey MD

Physician Director and Pain Consultant, Alcohol and Drug Treatment Program, Credit Valley Hospital, Mississauga, Ontario, President, Canadian Pain Society, 2005-2007

Speaker: Michael Salter MD PhD FRSC

Canada Research Chair in Neuroplasticity and Pain (Tier 1) Senior Scientist Head, Program in Neurosciences and Mental Health, Hospital for Sick Children and Professor of Physiology, University of Toronto Director, University of Toronto Centre for the Study of Pain, Toronto, Ontario; 2006 Distinguished Career Award Recipient, Canadian Pain Society

BRIEF DESCRIPTION: Dr Salter will discuss molecular and cellular mechanisms that underlie neuroplasticity of sensory processing in the spinal cord. He will focus on enhancement of excitatory amino acidmediated synaptic transmission and on the emerging role of neuron-glianeuron signaling in pathological pain.

\section{8:45 AM - SESSION 101}

3

THE NATURE AND NURTURE OF PAIN UNDERSTANDING THE PATHOPHYSIOLOGY AND THE IMPORTANCE OF GENETICS AND ENVIRONMENT Chair: Ellen Thompson MB BS FRCPC

Assistant Professor, University of Ottawa, Department of Anaesthesiology, the Ottawa Hospital, CPM Chronic Pain Management, Ottawa, Ontario, Local Arrangements Committee Chair, 2007

Speakers: Allan Basbaum PhD FRS Chair, Department of Anatomy, W.M. Keck Foundation Center for Integrative Neuroscience, University of California San Francisco, San Francisco, California Jeffrey S Mogil PhD, Department of Psychology and Centre for Research on Pain, McGill University, Montreal, Quebec

\section{$8: 45$ AM - SESSION 102}

\section{4} TRENDS IN OPIOID RELATED DEATHS

Chair: Mary Redmond MD FRCSC

Chronic Pain Management, Ottawa, Ontario

Speaker: Barry McLellan MD FRCPC

Chief Coroner for Ontario, Office of the Chief Coroner for Province of Ontario, Ministry of Community Safety and Correctional Services, Toronto, Ontario

\section{$8: 45$ AM - SESSION 103}

\section{5}

\section{METHADONE COURSE}

Chair: Linda Robinson MD CM FRCPC

American Board Certified (Anaesthesiology), Assistant Professor, University of Ottawa, Ottawa, Ontario

Speakers: Catherine Smyth MD PhD FRCPC, Bruce Marshall MD BEng CD, Ed Fitzgibbon MD MSc (Epi) CCFP

\section{A}

\section{METHADONE, PHARMACOLOGY AND USES IN CHRONIC} PAIN

Catherine Smyth MD PhD FRCPC

Department Anesthesia The Ottawa Hospital, Medical Director, The Ottawa Hospital Pain Clinic

\section{B}

METHADONE, TREATING PAIN VS ADDICTION, KNOWING THE DIFFERENCE

Bruce Marshall MD BEng CD

Special interest in HIV, addictions and chronic pain management, University of Ottawa Health Services, Ottawa, Ontario

\section{C}

METHADONE, USES IN PALLIATIVE CARE

Ed Fitzgibbon MD MSc (Epi) CCFP

Associate Professor, University of Ottawa, Medical Director

Palliative Care Program, The Ottawa Hospital, Ottawa, Ontario 


\section{8:45 AM - SESSION 104}

\section{6}

TRENDS IN OPIOID RELATED DEATHS

Chair: Mary Redmond MD FRCSC

Chronic Pain Management, Ottawa, Ontario

Speaker: Barry McLellan MD FRCPC, Chief Coroner for Ontario,

Office of the Chief Coroner for Province of Ontario, Ministry of Community Safety and Correctional Services, Toronto, Ontario

\section{8:45 AM - SESSION 105}

\section{7}

\section{METHADONE COURSE}

Chair: Linda Robinson MD CM FRCPC

American Board Certified (Anaesthesiology), Assistant Professor, University of Ottawa, Ottawa, Ontario

Speakers: Catherine Smyth MD PhD FRCPC, Bruce Marshall MD BEng CD, Ed Fitzgibbon MD MSc (Epi) CCFP

\section{A}

\section{METHADONE, PHARMACOLOGY AND USES IN CHRONIC PAIN}

Catherine Smyth MD PhD FRCPC

Department Anesthesia The Ottawa Hospital, Medical Director, The Ottawa Hospital Pain Clinic

\section{B}

\section{METHADONE, TREATING PAIN VS ADDICTION,} KNOWING THE DIFFERENCE

Bruce Marshall MD BEng CD

Special interest in HIV, addictions and chronic pain management, University of Ottawa Health Services, Ottawa, Ontario

\section{C}

METHADONE, USES IN PALLIATIVE CARE

Ed Fitzgibbon MD MSc (Epi) CCFP

Associate Professor, University of Ottawa, Medical Director, Palliative Care Program, The Ottawa Hospital, Ottawa, Ontario

\section{1:45 PM - SESSION 106}

\section{8}

FIBROMYALGIA SYNDROME: NEW VIEWS ON DIAGNOSIS, PATHOGENESIS, AND MANAGEMENT

Chair: David Mann C Eng FIET

President FM-CFS Canada, Ottawa, Ontario

Speaker: I lon Russell MD PhD

Associate Professor, The University of Texas Health Sciences

Center, San Antonio, Texas

\section{1:45 PM - SESSION 107}

\section{9}

\section{CARING FOR THE CHRONIC PAIN PATIENT WITH ACUTE PAIN}

Chair: Susan Madden BScN Med

Advanced Practice Nurse, Acute Pain Services, The Ottawa

Hospital, Ottawa, Ontario

Speaker: John Penning MD FRCPC
Associate Professor, Faculty of Medicine, University of Ottawa.

Medical Director, Acute Pain Service, Department of Anaesthesiology, the Ottawa Hospital, Civic Campus, Ottawa, Ontario

BRIEF DESCRIPTION: The incidence of chronic pain in Canada is estimated to be around $25 \%$ and is likely to increase with our aging population $(1,2)$. Opioid therapy for cancer pain has led to the acceptance of long term opioid therapy for patients with chronic non-cancer pain, albeit fraught with challenges and difficulties. The Acute Pain Service at the Ottawa Hospital, treats about 160 patients per week for acute pain related to surgery and trauma. Weekly, $5-10 \%$ of these patients are on long term opioids for cancer or non-cancer related chronic pain.

The patient receiving chronic opioid therapy is at risk for significantly increased acute pain after trauma or surgery, despite increased opioid usage $(3,4)$. There may be a genetic predisposition linking chronic pain, opioid tolerance, opioid induced hyperalgesia $(\mathrm{OIH})$ and an increased risk of chronic surgical pain (5). The concept of there being no "upper dose limit" for opioids is no longer accepted. High doses of opioids may have acute and chronic consequences, including activation of pro-nociceptive systems that actually exacerbate the patient's chronic pain (6). Therefore a major principle of management is to optimally implement, in a multimodal and pre-emptive fashion, non-opioid analgesic therapy, while maintaining chronic opioid dose levels, in order to avoid opioid dose escalation as much as possible. Modalities to consider include: regional anesthesia/analgesia, classical NSAIDs or coxibs, NMDA antagonists such as ketamine, dextromethorphan, intravenous lidocaine, oral clonidine, anti-convulsants such as gabapentin and pregabalin.

Chronic pain is almost always accompanied by anxiety and depression which should not be ignored. Non-pharmacological pain control modalities may also be of benefit, but are currently largely under utilized in most centers. An assessment of the patient's chronic pain and analgesic drug history should be performed prior to elective surgery. The Brief Pain Inventory, developed by Charles Cleeland, is quite helpful in documenting the impact of the patient's chronic pain and helpful in setting realistic acute pain management goals. A patient specific peri-operative analgesic plan is required and should be discussed with the patient, the surgical and nursing services. There is a need to improve the support these patients receive in the often difficult times following hospital discharge. Patients and their primary care physicians often require guidance with weaning off various analgesic drug therapies and titrating opioids back to chronic pain dosages used before the acute pain scenario.

\section{REFERENCES}

1. Millar WJ. Chronic Pain. Health Rep 1996;7:47-53.

2. Moulin DE, et al. Chronic Pain in Canada - Prevalence, treatment, impact and the role of opioid analgesia. Pain Res Manag 2002;7:179-84

3. Carroll IR, Angst MS, Clark JD. Management of Perioperative Pain in Patients Chronically Consuming Opioids. Reg Anesth and Pain Med 2004;6:576-91.

4. Hadi I, et al. Brief review: Perioperative management of the patient with chronic non-cancer pain. Can J Anesth 2006;12:1190-9.

5. Mitra S, Sinatra RS. Perioperative Management of Acute Pain in the Opioid-dependent Patient. Anesthesiology 2004;1:212-27.

6. Ballantyne JC, Mao J. Opioid Therapy for Chronic Pain. NEJM Nov 13, 2003; 1943-1953.

\section{1:45 PM - SESSION 108}

\section{0}

ROLE OF PSYCHE AND THE PSYCHOLOGIST IN CHRONIC PAIN

Chair: Ken Reesor PhD CPsych

Reesor Pigeon Psychology Professional Corporation, Ottawa, Ontario

Speaker: Џoel Katz PhD

York University, Department of Psychology, Toronto, Ontario, Department of Anesthesia and Pain Management, The Toronto General Hospital 
Learning Objectives:

1. To understand the role of psychological and emotional processes in the development and maintenance of chronic pain.

2. To understand the role, nature, and efficacy of various psychological interventions for chronic pain.

Pain that does not conform to present day anatomical and neurophysiological knowledge is often attributed to psychological dysfunction. The history of medicine is replete with examples of how pains that defied explanation based upon the science of the day - and were believed to be caused by psychopathology - ultimately were found to have neurophysiological underpinnings that were not related to the psychological disturbance. Living with chronic pain is sufficient to produce anxiety and depression. Living with chronic medically unexplained pain compounds the distress. Part one of this presentation will focus on identifying links between neurophysiological mechanisms of nociception in animals and the phenomenological experience of pain in humans. These links serve to reinforce the position that strange and unusual complaints of pain are not evidence of strange and unusual people. The idea that emotional and psychological processes can cause pain traditionally has been tied to the notion of psychopathology. The argument being made is not that psychological and emotional factors cannot trigger an experience of pain, but that psychopathology per se is not at the root of medically unexplained pain. Part two will focus on presenting current models of how psychological and emotional factors contribute to the development and maintenance of chronic pain. The roles of fear of pain, fear-avoidance beliefs, catastrophizing, and related constructs will be evaluated. Part three will take an evidence-based approach and focus on outlining the various psychological interventions that have demonstrated efficacy in helping patients manage their chronic pain.

\section{2:45 PM - SESSION 109}

\section{1}

\section{RATIONAL PHARMACOTHERAPY FOR THE TREATMENT OF CHRONIC PAIN}

Chair: John P Penning MD FRCPC

Associate Professor, Faculty of Medicine, University of Ottawa.

Medical Director, Acute Pain Service, Department of

Anaesthesiology, the Ottawa Hospital, Civic Campus, Ottawa

Ontario

Speaker: ME Lynch MD FRCPC

Director of Research and Acting Director, Pain Management Unit,

Queen Elizabeth II Health Sciences Centre, Halifax, Nova Scotia

\section{Learning Objectives}

1. The participant will develop an appreciation regarding how to introduce pharmacotherapy within an interdisciplinary approach to chronic pain management.

2. The participant will gain an appreciation for the major groups of medications used in the treatment of chronic non-cancer pain.

3. The participant will learn a rational step-by-step approach regarding which agents to introduce first and in combination based on the patient's symptoms.

Chronic pain involves multiple patho-physiological mechanisms with peripheral and central components. The management of chronic pain requires an interdisciplinary approach. Pharmacotherapy for chronic pain must take place within an overall management plan that maximizes the patient's involvement in the pursuit of health, even in the face of pain. This presentation will provide information regarding the major classes of medication used to assist in the management of chronic pain, including antidepressants and anticonvulsants. The use of chronic opioids will be reviewed along with discussion regarding topical approaches and an introduction to the field of cannabinoids.

\section{2:45 PM - SESSION 110}

12

\section{PSYCHOLOGICAL TRAUMA, ABUSE AND CHRONIC PAIN}

Chair: Joel Katz PhD

York University, Department of Psychology, Toronto, Ontario, Department of Anesthesia and Pain Management, The Toronto General Hospital

Speaker: Karen G Raphael PhD

Associate Professor, Director of Research Education, Department of Psychiatry, New Jersey Medical School, University of Medicine and Dentistry of New Jersey, Newark, New Jersey

\section{4:15 PM - KEYNOTE SPEAKER}

\section{3}

\section{ALTERNATIVE PEPTIDE-BASED APPROACHES TO THE USE OF OPIOIDS FOR THE TREATMENT OF PAIN}

Chair: John P Penning MD FRCPC

Associate Professor, Faculty of Medicine, University of Ottawa,

Medical Director, Acute Pain Service, Department of

Anaesthesiology, the Ottawa Hospital, Civic Campus, Ottawa,

Ontario

Speaker: Philippe Sarret PhD

Assistant Professor, CIHR New Investigator, Director of Sherbrooke Neuroscience Center, Department of Physiology and Biophysics,

Faculty of Medicine and Health Sciences, University of Sherbrooke, Sherbrooke, Quebec, 2006 Early Career Award Recipient, Canadian Pain Society

BRIEF DESCRIPTION: The pain system has an important protective role by alerting the individual to the threat of tissue damage. Chronic pain, on the other hand, serves no protective biological function and is a debilitating condition that exerts a high social cost in terms of productivity, economic impact and quality of life. Chronic pain has very complex and multifaceted features and cannot be understood by simply applying the concepts of acute pain and its treatments. Chronic pain responds poorly to NSAIDS and opioid analgesics and is resistant to most traditional therapies for pain. This presentation will focus on the implication of some G-protein-coupled receptors (GPCRs) in the processing of nociception and will evaluate whether these GPCRs are feasible targets for drug development to treat chronic pain

$$
\text { 7:00 PM - PURDUE PHARMA SYMPOSIUM }
$$

\section{4}

\section{THE "ART" OF PAIN MANAGEMENT: WHAT YOU AND YOUR PATIENT SHOULD KNOW BEFORE WRITING THE FIRST PRESCRIPTION}

Chair: Roman Jovey MD

Physician Director and Pain Consultant, Alcohol and Drug Treatment Program, Credit Valley Hospital, Mississauga, Ontario, President, Canadian Pain Society, 2005-2007

Speaker: Howard A Heit MD FACP FASAM

Board Certified in Internal Medicine and

Gastroenterology/Hepatology, Certified in Addiction Medicine and a Medical Review Officer, Chronic Pain Specialist, Assistance Clinical Professor, Georgetown University, Fairfax, Virgina

Learning Objectives:

1. Attendees will learn how to evaluate a chronic pain patient to determine if opioid medications are appropriate

2. Attendees will learn how to apply "Universal Precautions in Pain Medicine" in their practice.

The treatment of chronic non-cancer pain in a patient with or without the disease of addiction presents a challenging problem to a clinician. In many 
cases, use of opioid medication to treat chronic pain can be the "solution" or the "problem". It is important to perform a thorough evaluation of such a patient, before writing any prescriptions for a controlled substance, especially an opioid medication. At the initial evaluation, the clinician should tell the patient that the formulation of an appropriate treatment plan must be based on mutual trust and honesty. The clinician should ask the patient to choose three goals he/she hopes to achieve with an individualized treatment plan. If the patient has a history of substance misuse, the clinician must explain that acute pain can be treated in the face of an active drug misuse/addiction, but chronic pain cannot. Therefore, if opioids are to be considered, the treatment plan would have to include treatment for both pain and addiction. The clinician should explain the use of an opioid agreement for the treatment of non-cancer pain and the principles of "Universal Precautions in Pain Medicine," which include patient-centered urine drug testing for the benefit of the patient and the establishment of appropriate boundaries.

\section{FRIDAY MAY 25, 2006 SCIENTIFIC PROGRAM DAY ONE MAY 25, SCIENTIFIC PROGRAM DAY ONE}

\section{8:15 AM - KEYNOTE SPEAKER}

\section{5}

\section{UNDERSTANDING THE EPIDEMIOLOGY AND DEVELOPMENT OF CHRONIC PAIN}

Chair: Brian Cairns PhD RPh

Associate Professor \& Canada Research Chair, Faculty of Pharmaceutical Sciences, University of British Columbia, Vancouver, British Columbia, 2007 Scientific Program Chair Speaker: Elizabeth Van Den Kerkhof RN DrPH

Associate Professor, Anesthesiology, Nursing and Epidemiology, Queen's University, Kingston, Ontario

\section{Early Career Award Recipient, Canadian Pain Society}

INTRODUCTION: The epidemiology of pain is not clearly characterized. Many factors make pain a difficult phenomenon to study. Being a symptom rather than a disease, definitive biological markers are not available to confirm a diagnosis. Varied sampling strategies and the lack of a consistent definition contribute to the wide range of prevalence estimates in the literature. The etiology and outcomes of pain are also poorly understood.

METHODS: Common epidemiologic methods were used to describe the epidemiology of pain in the community and in hospitalized patients undergoing surgery. Secondary data from the National Population and Health Survey and the Canadian Multicentre Osteoporosis study were used to describe the epidemiology of pain in Canada. The Chronic Pain Grade was used to capture information on pain epidemiology in Southeastern Ontario, and the Pain Experience Interview - Short Form was used to assess pain in children. Prospective studies are currently underway to document pain after surgery and to assess the development of chronic postsurgical pain after surgery.

RESULTS: Community studies - Prevalence estimates of pain in the general population ranged from $15 \%$ to $66 \%$, depending on the definition used. Pain estimates in Southeastern Ontario - a largely rural region were slightly higher than the Canadian estimates. Fifty-seven percent of children aged 10-12 years reported recurrent pain, $6 \%$ reported chronic pain, and girls were more likely to report pain than boys. Children reporting pain had greater odds of decreased health status, adverse psychological outcomes and disliking school compared to children reporting no pain. Hospital studies - Postsurgical active pain scores in adults undergoing common surgical procedures ranged from $4 / 10$ (median) in the immediate post operative period to $3 / 10$ at 4 weeks. Older adults were less likely to receive a prescription for pain medication. Postoperative pain was associated with decreased physical functioning, but not mental functioning.

CONCLUSION: Over the past 6 years our research program has contributed some unique information to better understand the nature of pain.
Pain is clearly an important public health issue in the general population. Rural areas may be at greater risk of developing chronic pain, and children as young as 10 years of age are experiencing pain that impacts on their health, social and psychological outcomes. The Pain Experience Interview Short Form is the first tool to assess pain in children in the general population. In addition, my unique position as an epidemiologist in a department of anesthesiology has allowed me to apply epidemiological methods to study the impact of tissue injury on the development of chronic pain.

\section{0:00 AM - PLENARY SESSION 111}

\section{6}

WHAT'S NEW IN PEDIATRIC PAIN?

Chair: Jennifer Stinson RN PhD

Department of Anaesthesia, Hospital for Sick Children, Faculty of

Nursing, University of Toronto, Toronto, Ontario

Speakers: Lindsay S Uman BA Honours, Lori Palozzi MScN ACNP, Joelle Desparment MD

\section{A}

WHAT'S NEW IN PROCEDURAL PAIN?

Lindsay S Uman BA Honours

Clinical Psychology PhD Student, Dalhousie University and IWK

Health Centre, Halifax, Nova Scotia

Learning Objectives:

1. To provide an overview of well-validated measures of pain assessment for procedural pain

2. To provide updated evidence on empirically-supported psychological and pharmacological interventions for managing procedural pain

3. To review current guidelines for procedural pain management

Historically, procedural pain experienced by pediatric populations has been under-recognized and insufficiently treated, primarily due to misconceptions about pain development and expression in this vulnerable population. However, although we now recognize that infants and children experience pain in similar ways to adults, and that untreated pain can have longstanding psychological and neurophysiological effects, pediatric pain assessment and management continues to fall below optimal standards. In recent years, there have been important advances in our understanding of pediatric procedural pain assessment and management. The goal of this session is to provide researchers and clinicians with a current empiricallybased framework for the assessment and management of procedural pain in infants, children, and adolescents. First, an overview of commonly used well-validated measures for assessing pain in pediatric populations will be provided, including self-reports, observer-rated reports, and behavioural measures. Second, empirically-supported interventions for managing procedural pain based on recent systematic reviews will be discussed. This discussion will consider pharmacological interventions, but will focus primarily on psychological (cognitive-behavioral) interventions, which have been shown to be efficacious in reducing pain and distress. Finally, the session will end by reviewing recently published guidelines for the management of procedural pain in neonates, children, and adolescents, which will cover recommendations for the use of pharmacological and non-pharmacological interventions.

\section{B}

\section{WHAT'S NEW IN POSTOPERATIVE PAIN?}

Lori Palozzi RN MScN ACNP

Department of Anesthesia, Hospital for Sick Children, Toronto, Ontario

\section{Learning Objectives:}

1. Highlight relevant practice guidelines for post-operative pain in children.

2. Review the literature on post-operative pain assessment measures in children and adolescents.

3. Discuss the latest evidence on the pharmacological management of pain.

The management of post-operative pain in children remains a challenge 
despite the advances in knowledge over the past 30 years. This presentation will highlight relevant practice guidelines for post-operative pain in infants and children. Methods of measuring pain in the post-operative phase will be reviewed including self-report and observational scales. Recent literature on the management of pain will be reviewed with a focus on systemic and regional analgesia.

\section{$16 \mathrm{C}$}

\section{WHAT'S NEW IN CHRONIC PAIN?}

loëlle Desparmet MD

Department of Anesthesia, Multidisciplinary Chronic Pain Centre, Montreal Children's Hospital, Montreal, Quebec

Learning Objectives:

1. Review the main chronic pain syndromes in children and their evaluation.

2. Review of the literature and summarize the main points concerning the present state of the management of chronic pain in children.

It is estimated that 15 to $20 \%$ of children suffer from some form of chronic pain (1). Chronic pain is defined as pain continuing beyond the expected time of resolution of a trauma, surgical procedure or disease process. Chronic pain results in significant physical, emotional, psychosocial and financial cost to the child and his/her family and can be a burden on medical resources.

A child is a developing human being and the impact of chronic pain on his physical and emotional development can be long lasting. It may predispose the child for chronic pain in his adult life. School absenteeism, the equivalent of work absenteeism in adults, can result in academic failure and loss of future opportunities. Some children become withdrawn, isolated and sometimes depressed to the point of suicidal ideation. Chronic pain also often has an impact on the whole family and everyone's life is disrupted sometimes to a dramatic degree. The child's life, and often his family's, is on hold until the pain goes away at a crucial time of physical, social, intellectual and spiritual development.

The main objectives of the management of chronic pain in children are:

- restoration of physical function,

- return to school,

- normalization of family, social and personal life and well-being.

Physiotherapy, psychological and family interventions, and pharmacologi$\mathrm{cal} /$ non-pharmacological means constitute the mainstay of the treatment of chronic pain in children.

10:00 AM - SESSION 112

\section{7}

\section{INTERVENTIONAL APPROACH TO VISCERAL CANCER PAIN IN THE PALLIATIVE SETTING: A MODEL OF CARE AND TECHNICAL CONSIDERATIONS}

Chair: Dr Jeff Myers MD CCFP

Head - Palliative Care Consult Team, Sunnybrook Health Sciences Centre, Assistant Professor University of Toronto, Toronto, Ontario Speakers: Michael Gofeld MD FIPP, Department of Anesthesia, Pain Management Program, Sunnybrook Health Sciences Centre, Assistant Professor University of Toronto, Toronto, Ontario Dr Debbie Selby MD FRCP(C), Palliative Care Consult Team, Sunnybrook Health Sciences Centre, Toronto, Ontario Dr leff Myers MD MD CCFP MSEd, Head - Palliative Care Consult Team, Sunnybrook Health Sciences Centre, Assistant Professor University of Toronto, Toronto, Ontario

AIM: To enhance participant's awareness of the role of interventional techniques in managing visceral malignant pain.

Learning Objectives:

At the end of this 90-minute workshop, participants will be able to:

1. Identify appropriate cancer patients likely to benefit from interventional pain management

2. Demonstrate a knowledge of common neurolytic modalities

3. Demonstrate an understanding of common neurolytic procedures specific to visceral pain management
4. Manage pain medications following interventional procedures.

Pain is amongst the most common symptoms of advanced cancer. While the majority of patients can be managed with standard narcotics and adjuvant therapies the literature suggests that $\sim 10 \%$ of patients with advanced cancer will continue to experience refractory pain. Even patients followed specifically by palliative care specialists report ongoing severe pain despite adherence to step III of the WHO pain ladder (Klepstad et al 2005), and further, as demonstrated in the SUPPORT study, patients would opt for death over ongoing pain (McCarthy et al 2000). For this group of patients, interventional modalities offer an effective augmentation of the pain control.

Percutaneous interventional techniques can be grouped into anesthetic blockades and infusions, neurolytic procedures, and neuromodulation. Neurolytic techniques using physical (cryotherapy/radiofrequency ablation) or chemical (phenol/alcohol) approaches result in prolonged pain relief and can be used for both somatic pain and sympathetically mediated pain.

\section{0:00 AM - SESSION 113}

\section{8}

\section{CANNABINOIDS AND OPIOIDS IN A CLINICAL SETTING}

Chair: ME Lynch MD FRCPC

Director of Research and Acting Director, Pain Management Unit, Queen Elizabeth II Health Sciences Centre, Halifax, Nova Scotia Speakers: ME Lynch MD FRCPC, James Henry PhD, William

\section{Notcutt MD}

Learning Objectives:

1. Review the mechanism of action of cannabinoids and opioids in neuropathic pain, along with literature supporting synergistic actions.

2. Address the therapeutic options beyond the first line in neuropathic pain from various origins including multiple sclerosis (MS)

3. Gain clinical insight on the use of cannabinoids in combination with opioids as a treatment option for neuropathic pain.

By attending this workshop, you will be able to:

1. Discuss the preclinical evidence for a synergistic effect between cannabinoid and opioid systems in anti-nociception.

2. Describe initial clinical experience using cannabinoids in combination with opioids.

3. Be aware of the need for further research examining efficacy and safety issues when using cannabinoids and opioids in combination.

There is growing evidence that cannabinoids and opioids may have synergistic effects in animal models of pain. There is also some evidence of synergism in the clinical setting of experimental pain models. Further research is worthy to explore this promising avenue of synergistic interaction between cannabinoids and opioids in pain management.

The current workshop will present the preclinical evidence supporting synergy between cannabinoid and opioid systems and will review initial clinical work suggesting that the use of a cannabinoid in combination with an opioid may lead to lower opioid doses with fewer side effects and may improve analgesia. Dr James Henry will review the preclinical science, Dr Mary Lynch will present 3 case studies regarding patients who were able decrease their dose of opioid when using cannabis under the Marihuana Medical Access Regulations (MMAR) program and Dr William Notcutt will present clinical experience using a buccal preparation of cannabis extract (Sativex) in combination with opioids.

\section{A}

\section{CANNABINOID/OPIOID MECHANISMS OF ACTION IN ANIMAL MODELS}

\section{lames Henry PhD}

Michael G DeGroote Institute for Pain Research and Care, Hamilton, Ontario

The discovery of an endocannabinoid system in the early 1990's provided convincing evidence for the therapeutic use of cannabinoids. Thus far, 2 cannabinoid receptors have been cloned CB1 and CB2 receptors. 
Relevant to pain, the CB1 receptor is highly expressed in the nervous system such as in periaqueductal grey, spinal cord and primary sensory neurons. It is thought that endocannabinoids act as a retrograde messenger at synapses to inhibit neurotransmitter release such as glutamate, the main neurotransmitter implicated in pain. Opioids also play a major role in pain pathways. Although the mechanism of action is more well-defined than cannabinoids, it should be noted that cannabinoid receptors in the brain are 10 times more abundant than opioid mu-receptors and are expressed in areas relevant to pain pathways making the endocannabinoid system a strong player in pain modulation. Cannabinoids produce analgesia through the same brainstem circuit involved in opioid analgesia, however the use of an opioid is not required for the cannabinoids to produce this effect. Co-administration of $\Delta-9$-THC with $\mu$ opioid agonists can potentiate the anti-nociceptive effects of each agent. The pre-clinical evidence regarding cannabinoid-opioid synergy will be reviewed.

\section{B}

\section{EXPERIENCE WITH THE MEDICAL MARIJUANA PROGRAM (MMAR) AND OPIOIDS}

ME Lynch MD FRCPC

Director of Research and Acting Director, Pain Management Unit, Queen Elizabeth Health Sciences Centre, Halifax, Nova Scotia

The potent anti-nociceptive and antihyperalgesic effects of cannabinoid agonists in animal models of acute and chronic pain, the presence of cannabinoid receptors in pain-processing areas of the brain, spinal cord and periphery and evidence supporting endogenous modulation of pain systems by cannabinoids, provide support that cannabinoids exhibit significant potential as analgesics. There is also pre-clinical evidence supporting that there may be synergistic effects between opioid and cannabinoid systems. This raises the possibility that co-administration of cannabinoids and opioids may lead to improved analgesia and may allow a lower dose of each agent thus diminishing potential for side effects experienced at higher doses. Three case studies regarding patients who were able decrease their dose of opioid when using cannabis under the Marihuana Medical Access Regulations (MMAR) program will be presented.

\section{$18 \mathrm{C}$}

\section{ROLE OF SATIVEX® IN CLINICAL SETTING - OPEN DIALOGUE OF EXPERIENTIAL USAGE \\ William Notcutt MD \\ James Paget Hospital, Great Yarmouth, United Kingdom}

Due to the growing evidence of the role of cannabinoids in pain modulation, many clinicians adopt cannabinoids as a therapeutic option beyond the first line in pain management. There are 4 cannabinoid therapies available in Canada by prescription namely, nabilone (Cesamet $\left.{ }^{\circledR}\right)$, dronabinol (Marinol®), MMAR (government program) and THC:CBD 1:1 (Sativex ${ }^{\circledR}$ ). Sativex has been approved as an adjunctive treatment for the symptomatic relief of neuropathic pain in multiple sclerosis. The aim of this discussion is to present personal clinical experiences with Sativex used in combination with opioids in neuropathic pain management. In addition, the process of introducing Sativex therapy for pain control will be addressed along with challenges and opportunities and safety issues faced when prescribing Sativex.

\section{1:30 AM - HOT TOPICS IN PAIN RESEARCH STUDENT PRESENTATIONS}

\section{9}

Chair: Manon Choiniere PhD

Associate Professor, Department of Anesthesiology, Faculty of Medicine, University of Montreal; Clinical Scientist, Research Centre, Montreal Heart Institute, Montreal, Quebec Speakers: \anice I Montbriand MSc, Brittany Sauve MSc, Tammy M Klassen BA, Patricia C Emery BA (Hons)
19A

THE EFFECTS OF PATIENT GENDER AND ANGER ON TREATMENT AND APPRAISAL OF CHRONIC PAIN: A SIMULATION STUDY

lanice I Montbriand MSc

Department of Psychology, University of Northern British Columbia K Prkachin PhD, Department of Psychology, University of Northern British Columbia

Learning Objectives:

1. To describe research project related to the effect of patient gender and anger on treatment and appraisal of chronic pain.

AIM: To examine the effects of gender and anger on the evaluation of patients presenting with chronic shoulder pain, using a combination of audio vignettes and videotapes.

METHODS: One hundred thirty-one participants listened to audiotapes of a fictitious patient in a simulated doctor-patient interview. Male and female patients differed according to whether or not they presented as angry. Participants then watched a brief video of the patient undergoing a standard shoulder exam. Participants rated the sympathy they had for the patient, his or her pain level, control over their pain, rehabilitation potential, disability and how much support they would give the patient. Participants also chose between two treatments for each patient, one presented as involving greater pain than the other.

RESULTS: Angry patients received less sympathy and were viewed as being in more emotional distress than non-angry patients. Female patients received less sympathy, and were viewed as being in less pain, less disabled, and in more emotional distress than male patients. There was a trend towards viewing female patients as being poorer candidates for rehabilitation, and for participants to assign them to a harsher treatment choice than male patients.

CONCLUSIONS: The results suggest that female patients with chronic pain may be at risk of bias in assessment. Further research involving medical populations is suggested.

\section{B}

\section{INCREASED LEVELS OF CORTISOL IN HAIR IN PATIENTS WITH SEVERE CHRONIC PAIN}

Brittany Sauvé MSc ${ }^{\ddagger}$, Patricia Morley-Forster MD FRCPC ${ }^{\dagger}$, Lisa-Ann McKeough MD\$, Terri Paul MD FRCPC $\$$, Gideon Koren MD FRCPC $^{\ddagger}$ *, Stan Van Uum MD PhD ${ }^{\S}$

Dept of Clinical Pharmacology, University of Toronto, Toronto ${ }^{\ddagger}$, Depts of Anesthesia and Perioperative Medicine ${ }^{\dagger}$, Medicine $^{\S}$ and Pediatrics*, University of Western Ontario, London, Ontario

AIM: Although cortisol levels increase with acute stress, the relationship between chronic stress and cortisol level is less clear-cut with human studies finding both increased and decreased levels in urine, plasma and saliva. Recently, an increase in hair cortisol levels has been demonstrated in monkeys exposed to long-term stress of forced dislocation (1). We hypothesized that hair cortisol levels in humans may be used as a biomarker for chronic stress in a chronic non-cancer pain (CNCP) population (2).

METHODS: After local Research Ethics Board approval, adults with severe CNCP were recruited from patients referred for assessment of hypogonadal effects of long-term opioid use. Controls were recruited via media. All subjects completed the Perceived Stress Scale (PSS) which quantifies subjective stress for the previous 8 weeks. A hair sample of $20-50 \mathrm{mg}$ was obtained from the posterior vertex and suspended in methanol. Cortisol was measured using an ELISA immunoassay technique originally developed for assaying salivary cortisol (3).

RESULTS: Of 33 CNCP patients contacted, 15 agreed to participate and were compared to 39 controls. Hair cortisol levels were significantly increased in the CNCP group compared to controls $(93.3 \pm 43.7 \mathrm{pg} / \mathrm{mg}$ vs $56.1 \pm 32.1 \mathrm{pg} / \mathrm{mg}, \mathrm{P}<0.01)$. PSS scores were higher in $\mathrm{CNCP}$ group than in controls $(22.6 \pm 4$ vs $13.3 \pm 6.4, \mathrm{P}<0.01)$. The Pearson correlation between hair cortisol and PSS score was $0.23(\mathrm{P}=0.097)$.

CONCLUSIONS: Hair cortisol, a novel non-invasive biomarker for chronic stress, is elevated in patients with severe CNCP on opioids compared to controls (4). 


\section{REFERENCES}

1. Davenport MD, et al. Gen Comp Endocrinol. 2006.

2. McBeth J, et al. Arthritis Res Ther. 2005.

3. Yang HZ, et al. J Steroid Biochem Mol Biol 1998.

4. Ozyuvaci E, et al. J Pain Symptom Manage 2004.

\section{C}

\section{MULTIPLE INFANT INOCULATIONS, INCREASE IN PAIN} EXPRESSIONS

\section{Tammy M Klassen BA}

Department of Psychology, University of Northern British Columbia and Kenneth D Craig PhD, Department of Psychology, University of British Columbia, Prince George, British Columbia AIM: Multiple immunizations are given to infants at regularly scheduled intervals, 2, 4, 6, 12 and 18 months of age. Research has shown that single injections are painful, but the area of multiple injections has not been fully explored. The aim of this study was to determine if an infant's expression of pain increased with each inoculation given during a single visit.

METHODS: One hundred and eighteen 2, 4, 6 and 12 month old infants were given three routine inoculations at a normally scheduled pediatric check-up. 18 month old infants were excluded because they only receive 2 injections. The immunization procedure was videotaped with a DV recorder, and the visual data was later coded using Neonatal Facial Coding System (NFCS) and the Infant Body Coding System (IBCS) to determine expressions of pain.

RESULTS: The mean age of this sample was 130 days. Infants showed a significant increase in their overall expressions of pain, facial expressions and body movement, when the first injection was compared with the second injection and then compared with the third injection. Interestingly, the infants' expression of pain also increased significantly when the pain expressions from the second injection were compared with the third injection.

CONCLUSIONS: The principal results of this study showed that multiple inoculation injections during a single doctor's visit causes increasing amounts of pain expression in an infant. The increase in pain expression was not limited to one age group, but was seen in 2, 4, 6, and 12 month old infants.

\section{D}

\section{MULTIPLE INFANT INOCULATIONS: INCREASE IN PAIN EXPRESSIONS}

Tammy M Klassen BA

Department of Psychology, University of Northern British

Columbia, Prince George, British Columbia

\section{$19 E$}

\section{INSOMNIA IN CHRONIC PAIN PATIENTS WITH AND WITHOUT MAJOR DEPRESSIVE DISORDER}

Patricia C Emery BA (Hons)

School of Psychology, University of Ottawa, Ottawa, Ontario

Learning Objectives:

1. To understand the nature of insomnia as experienced by individuals with chronic pain and comorbid major depressive disorder, using both global and daily diary assessment measures.

2. To identify what aspects of cognitive-behavioural therapy for insomnia may be applicable to individuals with chronic pain and major depressive disorder.

Insomnia and major depressive disorder (MDD) are common problems among people with chronic pain (CP), but have seldom been studied together. In the present study, $33 \mathrm{CP}$ patients with MDD and $27 \mathrm{CP}$ patients without MDD underwent structured diagnostic interviews on sleep and mood, and completed retrospective and 4-day diary measures of sleep, sleep-related behaviours and cognitions, pain, and mood. A diagnosis of insomnia was highly prevalent in both groups, with $88.3 \%$ of all participants meeting DSM-IV criteria. Participants with MDD reported significantly higher levels of pain and more dysfunctional attitudes and behaviours related to sleep. However, specific sleep parameters such as sleep onset latency, time awake after sleep onset, sleep efficiency, and total sleep time did not differ between the groups. Partial correlation coefficients, controlling for pain severity, substantially decreased the associations between depression and cognitive-behavioural variables related to sleep, suggesting that pain may be more important than depression in the etiology of insomnia. The results are discussed in terms of the potential applicability of cognitive-behavioural interventions for insomnia in $\mathrm{CP}$ patients with comorbid MDD.

\section{1:30 PM - TRAINEE SESSION}

\section{0}

\section{KNOWLEDGE TRANSLATION: WHAT TRAINEES SHOULD KNOW IN PLANNING THEIR RESEARCH CAREERS}

Chair: Michael McGillion RN PhD

Faculty of Nursing and University of Toronto Centre for the Study of Pain, University of Toronto, Toronto, Ontario

Speakers: Bonnie Stevens RN PhD, University of Toronto, Faculty of Nursing and the Hospital for Sick Children, Toronto, Ontario Andy Dray PhD, Astra-Zeneca Research Centre, Montréal, Québec

\section{1:30 PM - SYMPOSIUM 114}

\section{1}

\section{PAIN IN OLDER PERSONS}

Chair: David Lussier MD FRCP(c)

Division of Geriatric Medicine, Pain Centre and Center for Research on Pain, McGill University, Montreal, Quebec Speakers: Lucia Gagliese PhD, R Sean Morrison MD, Thomas Hadjistavropoulos PhD RD Psych, David Lussier MD FRCP(c), Kim McKenzie MD FRCP(c)

\section{A}

\section{PAIN ACROSS THE ADULT LIFESPAN}

\section{Lucia Gagliese PhD}

York University and University Health Network, Toronto, Ontario A person's age plays an important role in pain throughout the lifespan. Age and developmental stage can impact on the neurobiology of pain, the ability to report pain, its meaning and consequences for developmental processes and attainment of life goals, physical abilities, and psychological, social and spiritual wellbeing. In adulthood, ageing and senescence are associated with multiple, non-uniform, interacting alterations across biopsychosocial systems, each of which may have an impact on responses to noxious stimulation, organic pathology and tissue injury, and the experience and impact of acute and chronic pain. The various interconnected systems must be considered together to arrive at an integrated understanding of both pain and aging. This presentation will provide an overview of the emerging evidence regarding age-related patterns in experimental and clinical pain. The impact of pain on physical, psychological and social wellbeing across age groups will be described, and biopsychosocial factors that may play important mediating roles in adjustment will be considered. Finally, an agenda for future research into aging and pain will be proposed.

\section{B}

\section{PAIN IN HOSPITALIZED OLDER PERSONS}

\section{R Sean Morrison MD}

Brookdale Department of Geriatrics and Adult Development, Mount Sinai School of Medicine, New York, New York

Pain is a major health quality issue in hospitalized patients. This presentation will focus on the problem of pain in hospitalized older adults using orthopaedic surgery as a research model. Specifically, the presentation will examine risk factors for the underassessment and treatment of pain, the effect of pain on outcomes in older adults, and describe a novel intervention to improve the management of post-operative pain using a series of studies that our group has performed. In patients with hip fracture, 
considerable delays in administering analgesic medications have been observed, as well as use of inappropriate analgesics (e.g., meperidine). Overcrowding of the emergency room negatively affects the quality of pain treatment received by patients. After surgery for hip fracture repair, undertreated pain and inadequate analgesia, as well as the use of meperidine, are risk factors for developing delirium and have been shown to result in increased hospital costs and delayed functional recovery. Finally, the presentation will include preliminary findings of a 4 year trial designed to improve the management of post-operative pain in adults undergoing lower extremity orthopaedic surgery.

\section{C}

PSYCHOSOCIAL APPROACHES TO PAIN MANAGEMENT FOR OLDER ADULTS WITH AND WITHOUT DEMENTIA Thomas Hadjistavropoulos PhD RD Psych

Department of Psychology and Centre on Aging and Health, University of Regina, Regina, Saskatchewan

Although in recent years there has been increasing literature attention on the topic of pain among older adults, work on psychosocial interventions designed to manage pain in this population has been quite scarce. This presentation will focus on two psychosocial pain management programs for older adults. Both programs were designed within the context of a Canadian Institutes on Health Research-Funded New Emerging Team. The first program, designed for seniors living independently, is based on cognitive behavioural principles and incorporates education about exercise and pharmacological management. The second program (which relies heavily on professional caregiver support) was designed for seniors who have dementia and reside in long-term care facilities. Findings and conclusions based on our initial evaluations of these programs (just completed) will also be presented.

\section{D}

\section{PHARMACOLOGICAL MANAGEMENT OF PAIN IN OLDER PATIENTS: AGE-RELATED PHARMACOKINETIC AND PHARMACODYNAMIC CHANGES}

\section{David Lussier MD FRCP(C)}

\section{Division of Geriatric Medicine, Pain Centre and Center for} Research on Pain, McGill University, Montreal

Aging is associated with several pharmacological changes. The main pharmacokinetic changes include a frequently decreased renal function that increases the half-life and risk of accumulation of renally-excreted medications, and an increased fat volume increasing the half-life of lipophilic medications and the serum concentrations of hydrophilic medications. Although less well-known, there are also some pharmacodynamic changes making older patients more at risk of adverse effects and complications from therapy. The polypharmacy often encountered in older patients also increases the risk of pharmacokinetic and pharmacodynamic drug interactions. When choosing a non-opioid, opioid or adjuvant analgesic, it is important to know its pharmacological properties, as well as the patient's morbidities and concomitant medications. This presentation will review the age-related pharmacological changes, focusing on drugs used for pain management.

\section{E PHARMACOLOGICAL MANAGEMENT OF PAIN IN OLDER PATIENTS: CHALLENGES FACED BY THE CLINICIAN Kim McKenzie MD FRCP(c)}

\section{Barrie, Ontario}

Pain management is often challenging in older patients, especially those with cognitive or functional impairment. In these patients, it is important to perform a comprehensive assessment including pain history, comorbidities, cognitive functions, functional status and social situation. Pain will be better addressed with a combination of non-pharmacological and pharmacological approaches, adapted to the specific needs of the patient. This presentation will review the main challenges faced by a clinician when treating pain in an older patient, and will provide ways to overcome some of these difficulties.

\section{1:30 PM - SESSION 115}

\section{2}

TEAM-BASED HEALTHCARE FOR DIFFICULT CHRONIC HEADACHE DISORDERS - WHAT ARE THE STRATEGIES AND IS IT EFFECTIVE?

Chair: Sharon Habermann PhD RPsych

Psychologist, Calgary Health Region Chronic Pain Centre, Calgary, Alberta

Speakers: Werner Becker MD FRCPC (Neuro), Neurologist, Calgary

Health Region Chronic Pain Centre, Calgary, Alberta

Sharon Habermann PhD RPsych, Psychologist, Calgary Health Region Chronic Pain Centre, Calgary, Alberta

lennifer Kirker RN BSN, Registered Nurse, Calgary Health Region

Chronic Pain Centre, Calgary, Alberta

Fern Yee BPE BSCPT Gunn-IMS, Physiotherapist, Calgary Health

Region Chronic Pain Centre, Calgary, Alberta

Francois Gagnon MES HBPE, Kinesiologist, Calgary Health Region

Chronic Pain Centre, Calgary, Alberta

\section{A \\ TEAM-BASED HEALTHCARE FOR DIFFICULT CHRONIC HEADACHE DISORDERS - WHAT ARE THE STRATEGIES AND IS IT EFFECTIVE?}

AIM: The aim of this workshop is to familiarize participants with the strategies of team-based multidisciplinary healthcare and its effectiveness for patients with difficult chronic headache conditions. Efficacy of teambased versus single-discipline (medical) care will be explored through review of original data from patients attending a multidisciplinary pain program and standard outpatient (medical only) headache clinic. Through case presentation, the presenters will review the key components of care for each discipline (medicine, psychology, physiotherapy, etc) during both assessment and treatment phases, and how the delivery of care occurs in an interdisciplinary manner (e.g., sequencing of cross-discipline treatments to maximize effectiveness). The respective roles of each discipline in the provision of team-based care will be discussed. Necessary interprofessional skills that foster effective team-based care will also be introduced.

Learning Objectives:

As a result of attending the workshop, participants will:

1. Know the efficacy of team-based care versus standard medical-only treatment for patients with chronic headache conditions.

2. Be familiar with the strategies of team-based healthcare for patients with chronic daily headache.

3. Know the key components of care and how it is delivered across disciplines (medicine, psychology, physiotherapy, kinesiology, nursing) during assessment and treatment phases.

4. Be aware of interprofessional skills proposed as necessary for effective teambased functioning.

The effectiveness of multidisciplinary teams has been well established in the treatment of chronic pain conditions such as low back pain (e.g., Flor et al, 1992; Guzman et al, 2002). However, the effectiveness of multidisciplinary teams in the specific treatment of chronic headache disorders has not been sufficiently investigated or confirmed. Using original data, the presenters will compare the effectiveness of a multidisciplinary team-based program compared to a traditional outpatient medical-only treatment for patients with chronic daily headaches. Based on the data, the presenters will suggest that consistent with other chronic pain conditions, multidisciplinary, team-based healthcare is superior to medical-only treatment for patients with chronic daily headaches. Then, through case presentation, the specific components of care and the roles of each team member will be described during both the assessment and treatment processes. Furthermore, how team-based care is actually structured and delivered to achieve positive outcomes will be expounded. Presenters will also propose what they view are the necessary interprofessional skills required for optimal multidisciplinary team functioning; skills believed transferable to team-based care for other chronic pain conditions. 
1:30 PM - SESSION 116

\section{3}

PAIN RELIEF/CONTROL FROM TRADITIONAL CHINESE
MEDICINE
WITHDRAWN

4:00 PM - SESSION 117

\section{4}

\section{EVIDENCE-BASED PRACTICE: PROMOTING INTEGRATION OF EVIDENCE INTO DAILY PRACTICE}

Chair: Suzanne Watt RN MSc (A)

Nursing, McGill University Health Centre, Montreal, Quebec Speakers: Suzanne Watt RN MSc (A), Nursing, McGill University Health Centre, Montreal, Quebec

Krista Brecht RN MSc (A), Nursing, McGill University Health Centre, Montreal, Quebec

AIM: Describe a process of integrating pain assessment and management principles in daily nursing practice using the Registered Nurses of Ontario (RNAO) Best Practice Guidelines (BPGs) engendering discussion among the participants around the challenges involved and feasibility in their respective institutions.

Learning Objectives:

The participants will be able to:

1. Describe principles of change

2. Identify facilitators and barriers to change in practice

3. Develop strategies for successful implementation of change

4. Consider evaluation methods for sustainability

The McGill University Health Centre (MUHC) is a five-site quaternary health care centre where the Nursing Executive Committee in conjunction with the Council of Nurses Executive identified pain management as a quality indicator of care. In 2004, the MUHC partnered with the Registered Nurses Association of Ontario (RNAO) to pilot the implementation of three Best Practice Guidelines (BPGs) outside the province of Ontario, one being The Assessment and Management of Pain. Advocates received training in Toronto to facilitate this process. Following a prevalence survey across the MUHC, implementation began on three volunteer pilot units, each from a different MUHC site. This required taking into consideration the cultural differences of each unit and site. The units selected bedside nurses who would become champions. Their responsibilities would include the education and mentoring of their peers. They attended a 4-hour workshop that included information on the content of the guidelines, principles of adult education and identification of roles and resource persons to support their efforts. Focus groups for champions were held at regular intervals during the implementation process to offer support and provide a forum for problem solving. The process of MUHC-wide implementation has been modified according to the lessons learned and continues to be fine-tuned. Managers have chosen a timeframe for implementation. The goal is to complete implementation on all inpatient units by the end of 2008 .

The workshop will describe the process in detail and provide the participants with opportunities to examine the feasibility of similar interventions in their respective institutions.

\section{4:00 PM - 5:30 PM -SESSION 118}

\section{5}

\section{CHRONIC PAIN AND HUMAN RIGHTS: VICTORIES AND} LOSSES

Chair: Heather Divine RN

President, Chronic Pain Association of Canada, Edmonton, Alberta

Speakers: Barry UImer, Claude Roberto PhD
AIM: The workshop will assess the victories and losses associated with chronic pain management in Canada in the last few years, with a recognition of the growing concern for human rights in Canadian society. The workshop will also demonstrate areas of improvement in public policy for Canadians who are concerned about their human rights protection in regards to pain management.

Learning Objectives:

1. Providing an update on current pain management from the patients' perspective.

2. Delivering information on how to improve access to care while not infringing on human rights.

3. Delivering information on the need to develop better public policy in regard to pain relief.

4. Describing educational activities conducted by the Chronic Pain Association of Canada to ensure patients' human rights are protected.

\section{A \\ HUMAN RIGHTS IN PAIN RELIEF \\ Barry Ulmer}

Executive Director, Chronic Pain Association of Canada, Edmonton, Alberta

Chronic pain destroys a person's ability to develop quality of life and to enjoy the pursuit of basic rights such as liberty. Therefore systems and structures unjustly denying access to therapies and medications reducing chronic pain infringe on a person's human rights.

In our society, two basic rights of people experiencing chronic pain are continuously thrashed: the right to dissemination of proper information on drug tolerance, dependence, addiction and abuse as well as equal access to treatments, medications and therapies reducing chronic pain. The workshop will explain how these basic rights are denied and will suggest a few solutions.

Misconceptions are spread by websites, the media, regulatory bodies, insurance companies, several scientific publications and word of mouth. Chronic pain is usually invisible and what is painful for some, is not for others. Fortunately, the Supreme Court of Canada in 2003 released an unanimous judgment stating the Nova Scotia Workers' Compensation Board limiting benefits for chronic pain patients infringed on the equality of rights protected by the Canadian Charter of Rights and Freedoms. However how far should the state be obligated to provide therapies?

Additional training offered to the medical community and regulatory bodies, education offered to the ones experiencing pain, improved communications between all parties, lobbying at all levels, and better funding for the groups able to provide education would be examples of solutions to implement if we really want to change misconceptions and protect people's rights.

\section{B}

\section{THE ALBERTA CAR INSURANCE REFORM AND HUMAN RIGHTS}

Claude Roberto PhD

Vice-President, Chronic Pain Association of Alberta, Edmonton, Alberta

People should have the ability to access the resources of the state in order to live a life of dignity and freedom according to article 22 of the Universal Declaration of Human Rights (1948). In Canada the Supreme Court confirmed that limiting pain relief was a form of discrimination. However is our Canadian universal health care able to provide therapies and medications to all people in need for them? If the state is not able to pay for these services, should it create public policies and legislation that prevents systems from unjustly denying patients pain relief?

In Alberta it is acceptable to deny pain relief if the medical conditions attached to car accidents do not fit predetermined types of injury. The amount of pain suffered by a patient has nothing to do with the amount of funding made available. The date of the accident, not the amount of pain, is the determining factor. The Alberta Bill 53, the Insurance Amendment Act 2003, was rushed through all three readings and royal assent between November 24 and December 4, 2003. It put a $\$ 4,000.00$ cap for pain on 
"minor sprains and strains" and forced chronic pain sufferers to be lumped into arbitrary funding categories. Regulations to define details of the car insurance reform relating to "minor" injuries were later defined without public debate by cabinet.

Is this an infringement of human rights? The workshop will examine if this Alberta approach is compatible with the Canadian Charter of Rights and Freedoms, and it will discuss options.

\begin{tabular}{c}
\hline SATURDAY MAY 26, 2007 \\
SCIENTIFIC PROGRAM DAY TWO \\
\hline
\end{tabular}

\section{7:30 AM - JANSSEN-ORTHO INC. SPONSORED SYMPOSIUM}

\section{6}

\section{MULTIMODAL ANALGESIA}

Chair: Yoram Shir MD

Associate Professor, Department of Anesthesia, Faculty of Medicine, McGill University, Montréal, Québec

Speakers: Dr Robert Raffa, Dr Jeff Gudin

\section{A}

MULTIMODAL ANALGESIA

\section{Robert B Raffa PhD}

Temple University School of Pharmacy, Philadelphia PA, USA

Learning Objectives:

1. To review the multi-modal nature of the anatomy and physiology of pain transmission.

2. To review the mono- or multi-modal mechanisms of action of current analgesic drugs.

3. To discuss the potential benefits and joint-action analysis of analgesic combinations.

Effective pharmacotherapeutic management of pain is particularly challenging because of the multiple 'types' of pain transmitted via multiple pathways and by multiple chemical mediators. The multi-modal nature of pain suggests that its treatment should be correspondingly multi-modal. However, most currently used analgesics have a predominant single mechanism of action (mono-modal) and therefore would not be expected to be completely effective against all types of pain. For example, NSAIDs inhibit cyclooxygenase-catalyzed conversion of arachidonic acid to prostaglandins and other chemical mediators. All NSAID effects (therapeutic and adverse) are believed to be directly or indirectly mediated by inhibition of cyclooxygenase isozymes (COX-1 and COX-2) either selectively or nonselectively. Opioid mechanism of action is also well understood. Most currently used opioids act primarily at 7-TM GPCR $\mu$-opioid receptors located at both central and peripheral sites. They inhibit presynaptic $\mathrm{Ca}^{2+}$ influx and postsynaptic $\mathrm{K}^{+}$efflux, inhibiting neurotransmitter release and hyperpolarizing postsynaptic neurons, respectively. A few analgesics, such as tramadol and perhaps acetaminophen, appear to multi-modal mechanisms, which might account for their clinical profiles. The multi-modal nature of pain is also a strong rationale for combining analgesic drugs of different mechanisms. Combination therapy targets more pain pathways than can a single drug, and different analgesics might have complementary pharmacokinetic profiles (for example, combining rapid onset with prolonged duration of action) or achieve synergistic analgesic effect (evaluated by joint-action analysis and isobolograms). Finally, multi-modal analgesia generally allows reduction of the doses required by mono-modal drugs, and can achieve an improved side-effect profile compared with monotherapy.
26B

REVIEW ANALGESIC OPTIONS, DISCUSS TRENDS IN ABUSE ADDICTION AND DIVERSION

Dr leff Gudin MD

Director of Pain Management at Englewood Hospital and Medical

Centre in Englewood, NJ, a teaching affiliate of the Mt. Sinai

University of Medicine

\section{8:45 AM - KEYNOTE SPEAKER}

\section{7}

\section{THE COMFORT OF TOUCH}

Chair: Susan Madden BScN Med

Advanced Practice Nurse, Acute Pain Services, The Ottawa

Hospital, Ottawa, Ontario

Speaker: Celeste lohnston RN DEd FCAHS

School of Nursing, McGill University, Montreal, Quebec, 2007 Distinguished Career Award Recipient, Canadian Pain Society BRIEF DESCRIPTION: Evidence for the analgesic effect of human touch from both animal and human literature will be presented, followed by discussion on incorporating touch into pain management strategies.

\section{0:30 AM - PLENARY SESSION}

\section{8}

EMERGING MECHANISMS OF ARTHRITIS PAIN

Chair: Brian Cairns PhD RPh

Associate Professor \& Canada Research Chair, Faculty of Pharmaceutical Sciences, University of British Columbia, Vancouver, British Columbia, 2007 Scientific Program Chair Speakers: \ason McDougall PhD, James Henry PhD, Volker Neugebauer MD PhD

\section{A NEUROPHYSIOLOGICAL PROCESSES IN THE JOINT RESPONSIBLE FOR THE DEVELOPMENT OF ARTHRITIS PAIN}

Jason McDougall PhD

Associate Professor, AHFMR Scholar, Arthritis Society Investigator, Department of Physiology and Biophysics, University of Calgary, Calgary, Alberta

Learning Objectives:

1. Attendees will learn about the physiological processes which occur in primary afferent nerves which lead to the generation of joint pain.

2. This presentation will also highlight our recent work which identified some of the neurochemical pathways which contribute to the development of osteoarthritic pain.

Synovial joints are richly innervated with sensory nerves whose primary function is to sense the mechanical environment of the joint. Using complex electrophysiological recording techniques, we have recently identified mechanosensitive ion channels on the terminals of joint afferents [1]. These ion channels only open following mechanical deformation of the axon membrane leading to nerve depolarisation and action potential generation. These mechanogated ion channels are the molecular machinery responsible for the transduction of a mechanical stimulus into an electrical nerve impulse.

In an animal model of osteoarthritis (OA), we discovered that knee joint afferents increase their firing rate and this is in part due to the activity of a neuropeptide called vasoactive intestinal peptide (VIP) [2]. Local administration of a VIP antagonist successfully blocked this sensitization of joint nerves. In other studies, we have determined that local administration of a cannabinoid that is selective for the CB1 receptor also inhibited nociceptor firing rate in the OA knee. These findings highlight two pathways that show therapeutic promise for the amelioration of OA pain. 


\section{REFERENCES}

1. Hepplemann B, McDougall JJ. Inhibitory effect of amiloride and gadolinium on fine afferent nerves in the rat knee: Evidence of mechanogated ion channels in joints. Experimental Brain Research 2005;167: 114-8.

2. Schuelert N, McDougall JJ. (2006). Electrophysiological evidence that the vasoactive intestinal peptide receptor antagonist $\operatorname{VIP}(6-28)$ reduces nociception in an animal model of osteoarthritis. Osteoarthritis and Cartilage 2006;14: 1155-62.

\section{B}

\section{PRIMARY AFFERENT CHANGES IN AN ANIMAL MODEL OF OSTEOARTHRITIS}

lames Henry PhD, Michael G DeGroote

Institute for Pain Research and Care, Hamilton, Ontario

\section{C}

THE AMYGDALA: SUPRASPINAL MODULATION OF ARTHRITIC PAIN

Volker Neugebauer MD PhD

Associate Professor, Department of Neuroscience \& Cell Biology, The University of Texas Medical Branch, Galveston, Texas

\section{2:30 PM - PFIZER-SPONSORED SYMPOSIUM}

\section{9}

THE TRIAD: PAIN, SLEEP \& MOOD

Chair: Ellen Thompson MB BS FRCPC

Assistant Professor, University of Ottawa, Department of Anaesthesiology, Chronic Pain Management, The Ottawa Hospital, Local Arrangements Committee Chair, 2007, Ottawa, Ontario Speakers: John Clark MD FRCPC, Director, Chronic Pain Centre, Calgary Health Region, Clinical Professor of Anesthesia, University of Calgary, Calgary, Alberta

Brian Murray MD FRCP(C) D, ABSM Neurology and Sleep Medicine, Assistant Professor, University of Toronto, Department of Medicine, Director, Sleep Program, Sunnybrook Health Sciences Centre, Toronto, Ontario

Robert Hewko MD FRCPC BSc (Honours) Biochem, Clinical Associate Professor, University of British Columbia, Faculty of Medicine, Department of Psychiatry Clinical Director, Psychiatric Consultation Service, Vancouver Hospital and Health Sciences Centre, Vancouver, British Columbia

Learning Objectives:

1. Understand the triad of pain, i.e., the relationship between pain, sleep and mood

2. Optimize treatment outcomes of Neuropathic Pain patients by managing cofactors and comorbid conditions of Neuropathic Pain

3. Improve function and quality of life of Neuropathic Pain patients through effective treatment of pain and its comorbidities and co-factors

Neuropathic Pain frequently leads to the emergence of a complex set of physical and psychosocial complications, such as sleep disturbance and anxiety, which results in markedly reduced quality of life and imposes a severe financial and personal burden. In order to effectively manage patients with Neuropathic Pain, pain, sleep and anxiety must be accurately and comprehensively assessed. In the course of this session, experts will broach the assessment and treatment of Neuropathic Pain within the context of the triad of pain, sleep and anxiety.

\section{2:00 PM - SESSION 119}

\section{0}

\section{WAITING IN PAIN}

Chair: Philip Peng MBBS FRCPC

Wasser Pain Management Center and Anesthesia Chronic Pain
Program, University Health Network and Mount Sinai Hospital, Toronto, Ontario

Speakers: Philip Peng MBBS FRCPC ${ }^{1}$, Mary Lynch MD FRCPC ${ }^{2}$, Mike Dunbar MD FRCSC ${ }^{3}$, Hon Carolyn Bennett PC MP MD ${ }^{4}$, Anne Fouillard BA MES $^{5}$

${ }^{1}$ Director, Anesthesia Chronic Pain Program, University Health Network, Director of Research, Wasser Pain Management Center, Toronto, Ontario; ${ }^{2}$ Director of Research and Interim Director, Pain Management Unit, QEII Health Sciences Center, Halifax, Nova Scotia; ${ }^{3}$ Associate Professor, Division of Orthopedic Surgery, Dalhousie University, QEII Health Sciences Center, Halifax, Nova Scotia; ${ }^{4}$ Member of Parliament, St. Paul's Riding, Past Minister of State for Public Health; ${ }^{5}$ Consultant CIDA

Learning Objectives:

1. Participants will be able to understand limited resource, distribution and wait time of multidisciplinary pain clinics across Canada.

2. Participants will learn about the results of a recent systematic review on wait times benchmarks completed by the Canadian Pain Society's Wait Times Task Force along with a discussion about the biological and psychosocial impact of delaying treatment.

3. Participants will be able to understand on a personal level of how a patient feels while waiting for treatment of pain.

4. Participants will learn about the wait times for joint replacement initiative.

5. Participants will learn from the perspective of a politician how they plan to improve access to care for patients suffering with chronic pain.

Chronic pain affects one out of five Canadians and is more prevalent than other chronic illness such as diabetes mellitus or asthma. The control of pain has been a relatively neglected area of governmental concern despite the fact that cost-effective methods of pain control are available. The objective of this forum is to highlight the problem of unduly long waiting time for those chronic pain sufferers waiting for the treatment from multidisciplinary pain treatment facilities (MPTF).

The speakers will summarize the wait time for the MPTF in various provinces in Canada, present the results of a recent systematic review on wait times benchmarks completed by the Canadian Pain Society's Wait times Task Force, discuss the biological and psychosocial impact of delaying treatment for chronic pain sufferers and present the experience of work by orthopedic surgeons on the issue of wait times in patients waiting for arthroplasty. A patient representative will discuss the issue of waiting from a personal perspective, and a politician will address the issue of wait times for chronic pain from the legislator's perspective.

\section{$30 \mathrm{~A}$}

WAIT TIMES IN MULTIDISCIPLINARY PAIN CLINICS IN CANADA

Philip Peng MBBS FRCPC

Director, Anesthesia Chronic Pain Program, Department of Anesthesia and Pain Medicine, University Health Network, Toronto, Ontario

\section{B}

RESULTS OF THE CANADIAN PAIN SOCIETY WAIT TIMES TASK FORCE

ME Lynch MD FRCPC

Department of Psychiatry, Dalhousie University and Queen

Elizabeth II Health Sciences Centre, Halifax, Nova Scotia

30C

WAITING IN PAIN - A PATIENT'S EXPERIENCE

Anne Fouillard BA MES

Consultant CIDA

30D

EXPERIENCE FROM ORTHOPEDIC SURGEONS ON JOINT REPLACEMENT WAIT TIMES

Michael Dunbar MD FRCSC

Associate Professor, Division of Orthopedic Surgery, Dalhousie University, QEII Health Sciences Centre, Halifax, Nova Scotia 
30E

WAIT-TIMES - A POLITICIAN'S PERSPECTIVE

Hon Carolyn Bennett PC MP MD

Member of Parliament, St. Paul's Riding, Past Minister of State for Public Health

\section{2:00 PM - SESSION 120}

\section{1}

\section{USING QUALITATIVE SENSORY TESTING (QST) IN CHRONIC PAIN EVALUATION: FROM RESEARCH TO CLINICAL PRACTICE}

Chair: Pam Squire MD CCFP

Lions Gate Hospital, Department of Family Practice, UBC Clinical Instructor, North Vancouver, British Columbia

Speakers: Pam Squire MD CCFP, Serge Marchand PhD, Mark Ware MBBS MRCP(UK) MSC

Learning Objectives:

1. Review sensory abnormalities in neuropathic pain (i.e. static and dynamic tactile allodynia, cold hyperalgesia, temporal summation etc) and discuss underlying mechanisms (Squire).

2. Discuss the evidence for the utility of QST in guiding treatment options in complex pain disorders such as fibromyalgia (Marchand)

3. Discuss practical clinical issues in performing QST in the clinical environment (Ware)

This workshop reviews the data on mechanistic approaches for the diagnosis and treatment of chronic pain. The focus will be on the utilization of quantitative sensory testing (QST) to characterize the somatosensory phenotype of patients with neuropathic pain. The review will include current research paradigms but will primarily focus on how to utilize and incorporate simple bedside QST into everyday clinical practice. The session will be interactive and there will be extensive opportunity for discussion of practical issues.

\section{$31 \mathrm{~A}$}

REVIEWING SENSORY ABNORMALITIES IN PAIN

Pam Squire MD CCFP

Lions Gate Hospital, Department of Family Practice, UBC Clinical Instructor, North Vancouver, British Columbia

\section{B}

\section{USING QST TO CLARIFY THE ROLE OF A DEFICIT OF ENDOGENOUS PAIN INHIBITORY MECHANISMS IN FIBROMYALGIA}

Serge Marchand PhD

Professeur titulaire, Chaire en douleur UQAT-UdeS, Université de Sherbrooke, Faculté de médecine, neurochirurgie, Montreal, Quebec

\section{$31 \mathrm{C}$}

QUANTITATIVE SENSORY TESTING IN CLINICAL PRACTICE: A PRACTICAL DEMONSTRATION AND FEASIBILITY DISCUSSION

\section{Mark Ware MBBS MRCP(UK) MSC}

MUHC Pain Clinic, Departments of Anesthesia and Family Medicine, McGill University, Montreal, Quebec

\section{2:00 PM - SESSION 121}

\section{2}

\section{ACCEPTANCE- AND MINDFULNESS-BASED APPROACHES} IN THE TREATMENT OF CHRONIC PAIN

Chair: Gregg Tkachuk PhD

Chronic Pain Centre, Saskatoon Health Region and Department of Physical Medicine and Rehabilitation, College of Medicine,

University of Saskatchewan, Saskatoon, Saskatchewan

Speakers: Gregg Tkachuk PhD, Marc Woods PhD

AIM: To introduce attendees to the rationale for acceptance-based treatment approaches and Acceptance and Commitment Therapy (ACT) for chronic pain and to demonstrate selected practical exercises based on these approaches.

Learning Objectives:

1. Participants will be able to define and understand pain-related acceptance as it is conceptualized in ACT and other acceptance-based therapies.

2. Participants will learn about the ACT model for chronic pain and the core therapeutic processes involved in implementing an ACT-based therapy protocol.

Brief Description: Recent scientific developments have ushered in a "new wave" of behavior therapy within the field of clinical psychology and, more specifically, within the area of chronic pain treatment. While traditional cognitive-behavioral approaches have often targeted control of dysfunctional cognitions related to pain with the ultimate goal of reducing or even eliminating pain, acceptance-based approaches (e.g., Dahl, Wilson, Luciano, \& Hayes, 2005) encourage increased willingness to experience pain (as well as pain-related thoughts, feelings, and other physical sensations) and engagement in values-directed activities through the use of exercises (e.g., mindfulness) designed to alter the functional contexts that have occasioned pain-related suffering. The first presentation will describe the theory/philosophical assumptions, core therapeutic processes, and research evidence for Acceptance and Commitment Therapy (ACT) for chronic pain. The second presentation will introduce practical acceptance-based techniques that have been implemented to help patients let go of their struggle with pain and mindfully get back into their lives.

\section{A}

ACCEPTANCE-BASED TREATMENT FOR CHRONIC PAIN: THEORY, CORE THERAPEUTIC PROCESSES, AND RESEARCH Gregg Tkachuk PhD

Chronic Pain Centre, Saskatoon Health Region and Department of Physical Medicine and Rehabilitation, College of Medicine,

University of Saskatchewan, Saskatoon, Saskatchewan

This presentation will describe the theory/philosophical assumptions, core therapeutic processes, and research evidence for Acceptance and Commitment Therapy (ACT) for chronic pain. Within this model, painrelated suffering is a direct result of unwillingness to experience pain (and pain-related thoughts and feelings) and the struggle that ensues in attempting to control or eliminate it. Pain-related acceptance has been defined as a willingness to experience pain (without attempting to change it) in the service of engaging in valued life directions (McCracken, 2005). Pain-related suffering is largely the result of the way basic human language processes habitually interfere with mindful experiencing in the present moment. This process in turn contributes to the experiential avoidance and psychological inflexibility observed in many chronic pain patients. The core therapeutic processes in ACT include: letting go of the struggle (acceptance), defusing the power of language, being present (mindfulness), self as observer, valuing, and committed action. Available research suggests that ACT strategies compare favorably to CBT strategies in laboratory pain tolerance studies (e.g., Hayes et al, 1999; Gutierrez et al, 2004), and that ACT improves emotional and physical functioning, lowers health care utilization, and reduces pain-related work absenteeism when applied in clinical settings with chronic pain patients (Dahl et al, 2004; McCracken et al, 2006. 


\section{B}

STRATEGIES FOR ENHANCING PAIN-RELATED ACCEPTANCE AND MINDFULNESS

\section{Marc Woods PhD}

Chronic Pain Centre, Saskatoon Health Region

This presentation will introduce practical therapeutic techniques and guidelines to complement the theoretical overview of acceptance-based treatment for chronic pain discussed in the first presentation. These strategies and techniques are designed to help clients let go of their struggle with pain, increase their awareness of how language contributes to this struggle, live more mindfully in the present moment, identify their values, and commit to living their lives in accordance with these valued directions. The techniques and strategies reviewed and demonstrated will include an overview of the use of metaphors that are introduced to achieve specific therapeutic effects (e.g., letting go of the struggle with pain, defusing language, making room for pain) and experiential (mindfulness) exercises. Many of these techniques can be used in isolation, integrated within other therapies, or form the backbone of an acceptance-based treatment.

\section{2:00 PM - SESSION 122}

\section{3}

LONG-TERM CONTINUOUS INTRAVENOUS LIDOCAINE FOR THE TREATMENT OF INTRACTABLE CANCER PAIN: AN INTERDISCIPLINARY APPROACH

Chair: Catherine Smyth MD PhD FRCPC

Department Anesthesia The Ottawa Hospital, Medical Director, The Ottawa Hospital Pain Clinic

Speakers: Catherine Smyth MD PhD FRCPC, Department Anesthesia The Ottawa Hospital, Medical Director, The Ottawa Hospital Pain Clinic

Virginia M Jarvis RN RM BScN MPC, The Ottawa Hospital Regional Cancer Centre, Department of Palliative Care, Ottawa, Ontario

AIM: Short-term infusions of intravenous (IV) lidocaine have been used in pain clinics for the treatment of neuropathic pain for many years. However, the use of continuous IV lidocaine infusions for the treatment of severe cancer pain is an emerging treatment modality for palliative patients. The aim of this workshop is to discuss the use of IV lidocaine in this palliative population and enable participants to incorporate this treatment modality into their practice.

Learning Objectives:

Using case studies, this workshop will enable participants to understand the:

1. Selection criteria for continuous intravenous lidocaine infusion.

2. Initiation of infusion through bolus dosing.

3. Continuation guidelines.

4. Side effect profile.

5. Monitoring serum levels.

6. Drug interactions.

7. Development of policy and procedures.

8. Development of education programs for inpatient and community care.

\section{A}

\section{Catherine Smyth MD PhD FRCPC}

Many patients with a diagnosis of cancer will experience pain at some time during their illness, with advanced cancers exhibiting more severe and complex pain syndromes. Of these patients, approximately $34 \%$ will develop pain of neuropathic origin. The treatment of nociceptive pain has improved substantially over the last 20 years; however, effective treatment for neuropathic pain remains elusive (Portenoy \& Lesage 1999). Intravenous (IV) lidocaine has been reported to relieve pain of varying origins (Challapalli V. et al, 2005). Lidocaine is also an analgesic and can relieve acute and chronic pain. In pain clinics, it has traditionally been administered as a short-term infusion (30-60 minutes) resulting in pain relief of days to weeks.
We have initiated continuous IV lidocaine therapy in refractory patients with a variety of diagnoses including but not limited to: cutaneous metastases, brachial and sacral plexopathies, with encouraging results. A retrospective summary of these patients will be presented. Several patients improved to such a degree that they were discharged home with continuous IV lidocaine infusing via a portable pump. Patients were followed through regular appointments in the pain clinic for many months following initiating of IV lidocaine. Adverse reactions to IV lidocaine were uncommon and easily treated. We have found continuous IV lidocaine to be a safe and effective means of managing refractory cancer pain in both inpatient and home settings.

\section{B}

\section{Virginia M larvis RN RM BScN MPC}

Lidocaine acts as a sodium channel blocker and membrane-stabilizing agent and is used as an anesthetic and an anti-arrhythmic. As such, IV lidocaine is routinely administered in a monitored setting. Logistically, however, it is not practical to isolate palliative patients in the cardiac monitored milieu. There are a limited number of case reports that describe the continuous administration of subcutaneous and IV lidocaine for the relief of intractable cancer pain in the hospital setting.

Following the initiation of IV lidocaine in our facility, real concerns were expressed by pharmacy, nursing, medical staff and Senior Management in caring for the patients without cardiac monitoring. These concerns provoked anxiety in both the inpatient hospital and community settings. To address these issues, education programs were developed. Policy and procedures were written and approved by Senior Management for safe and consistent care of patients suffering with intractable neuropathic pain receiving continuous IV Lidocaine. Education material was also developed for the patient and family members. These strategies can be applied for all novel treatment modalities. 


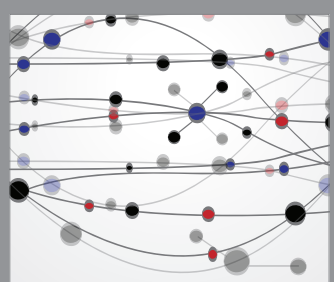

The Scientific World Journal
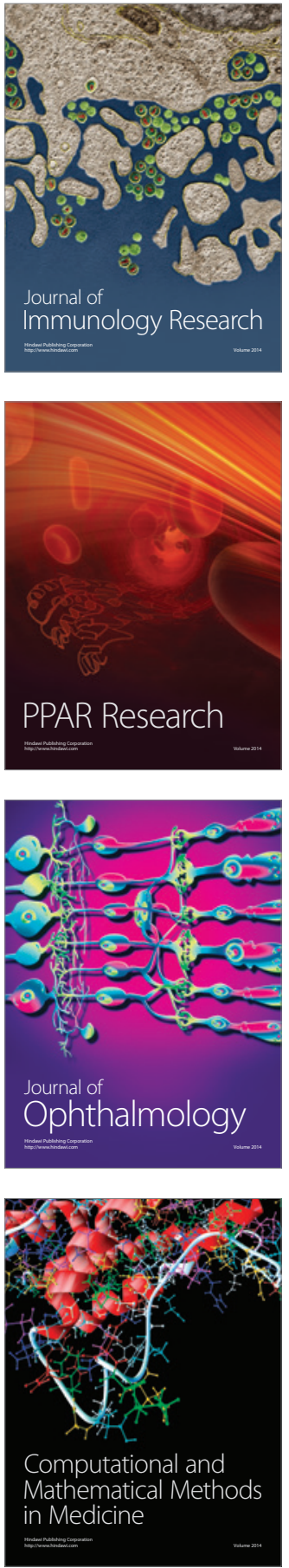

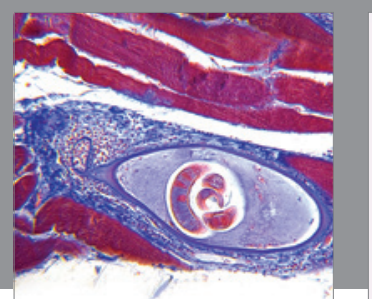

Gastroenterology Research and Practice

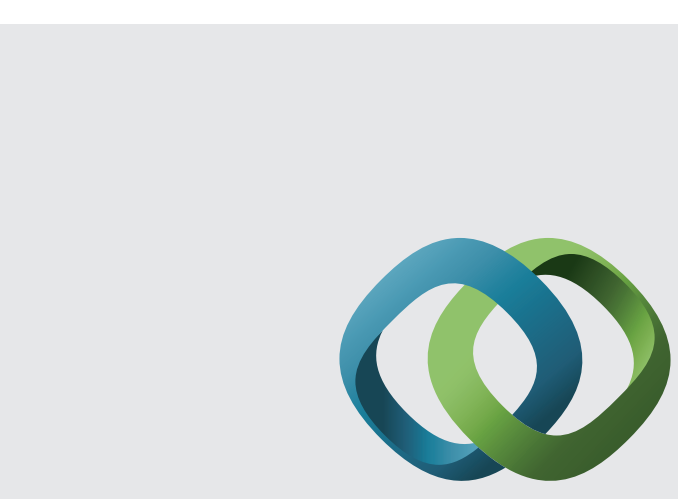

\section{Hindawi}

Submit your manuscripts at

http://www.hindawi.com
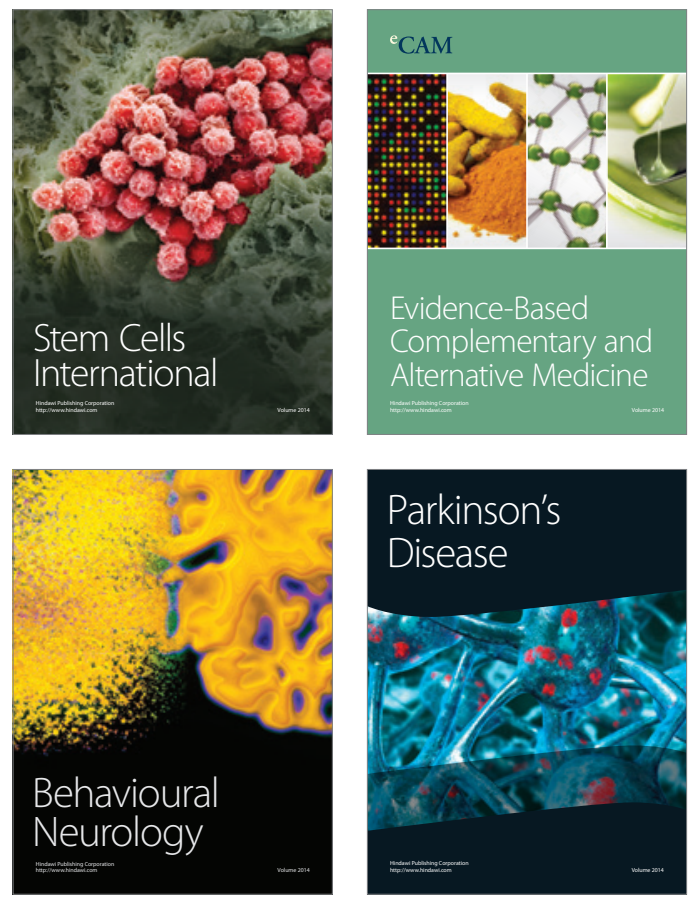
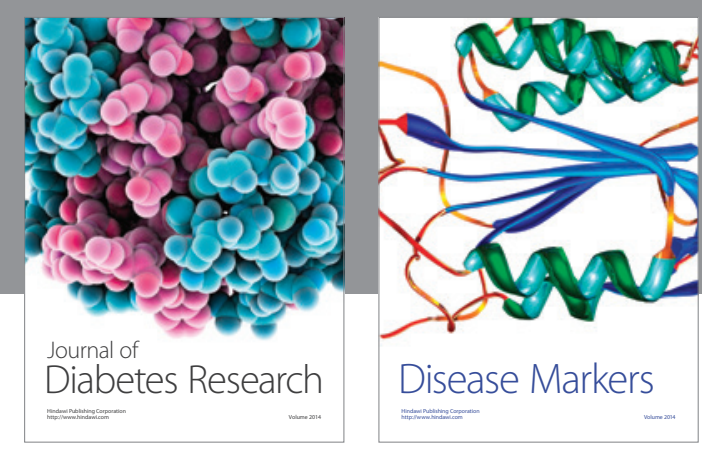

Disease Markers
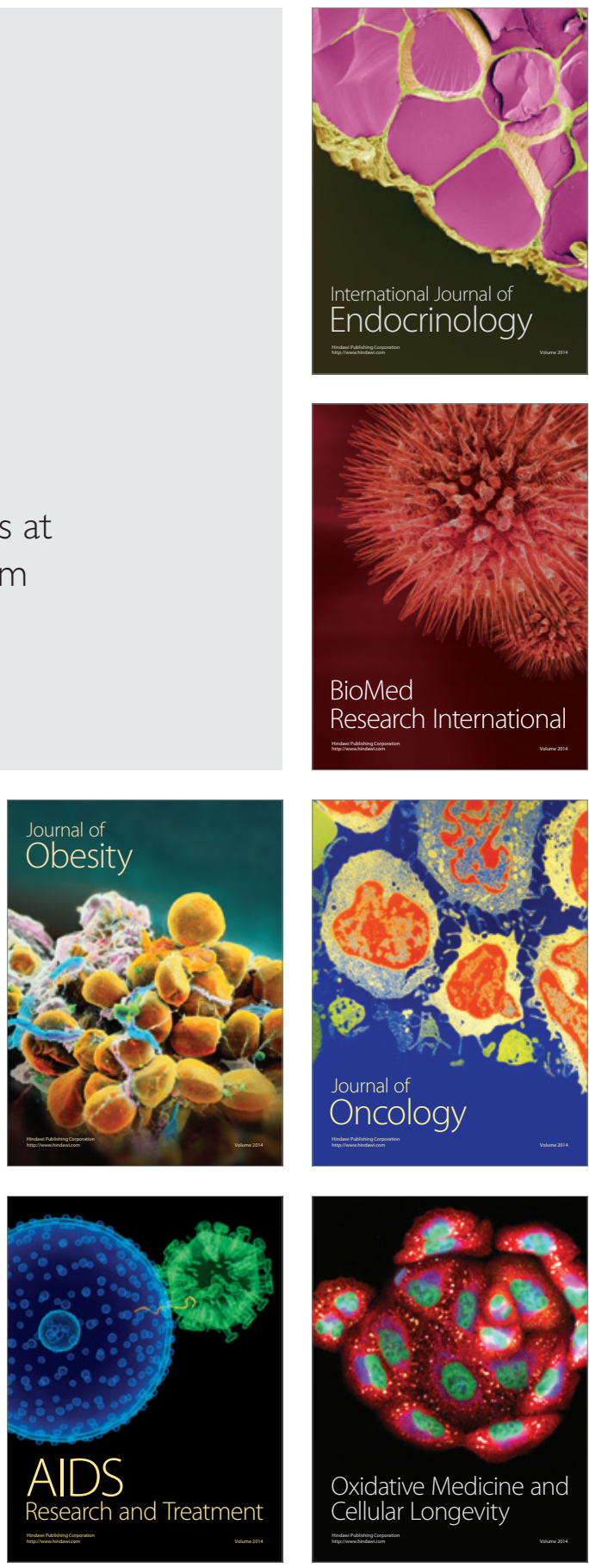